\title{
Appropriate Methodology for Development Research*
}

D. G. R. Belshaw

To take action on the assumption that knowledge per se is good is not rational behaviour but academic prejudice. It is a great mistake for us to behave as if research data were going to be used, if they are not. Their mere presence does not conjure forth a change in the reality.

Andreas Fuglesang (1972:119)

Attempts to evaluate the benefits of development research are hampered both by the absence of $e x$ post procedures for identifying the final impact of research results and the lack of studies on the nature of causality in this area. Also, obscurity results from the conventions surrounding research presentation and academic output, which do not encourage explicit discussion of important features of the research methodology employed. The techniques of data collection and analysis may be described, but discussion is rare on how and why the research problem was identified and selected; factors in the choice of theoretical framework, model design and the specific variables included and omitted; choice between alternative hypotheses; data reliability. replicability of methods and results, and stages in the verification and application of the practical recommendations (if any).

Fuglesang implies that there are two criteria for the evaluation of applied research-whether the results are usable and whether the results are actually used in decision-making to bring about the changes desired. Is the second criterion relevant? Many researchers, after accepting some responsibility for the clear presentation of results and their dissemination to potential users, will maintain that it is not. They will argue that whether and how the results are finally used is not their responsibility. Yet not only the probability of providing usable results but also the probability of the results being used effectively is affected by a variable within the researcher's domain-the choice of research methodology.

\footnotetext{
* The central argument in this paper is derivad from two years' regional planning programmes in tha Ministry of Finance and regional planning programmes in tha Ministry of Finance and sible by a financial grant from the Ministry of Overseas Development. Part of the paper was presented at a conference of the Agricultural Economics Society held at $W$ ye College in December, 1972 .
}

\section{A Case Study of a Research-Planning-Develop- ment System}

In a simple conceptual model, the connection between the choice of research methodology, on the one hand, and change in the development status of an economy, or part of it, on the other, may be viewed as proceeding through three linked processes. This is portrayed in simplified flow chart form in Figure 1. The analysis is restricted to one sector of an economy only. Starting with the development process itself (process III) on the right hand side of the diagram, the output side $Q$ (which would be analysed in terms of the relevant social objective functions--physical product, income distribution, regional balance, etc.) is affected by the quality of agricultural planning decisions $(P)$ which join several other independent variables $(R, S, T)$ as inputs into the process. The planning decisions are themselves outputs from planning activity (process II). Here, the output of applied research activity ( $Y$ ) is one of several variables including planning techniques (U), planning manpower (V), and statistical services (W), which comprise the input side. Finally, the output from applied research activity (process I) is viewed as dependent on the research methodology employed $(\mathrm{X})$, the research funds $(\mathrm{K})$ and researchers (L) available, and the research access (M) provided. Secondary linkages between these variables, e.g., between research resources and research methodology are not indicated on the chart. Two of several possible feed-back linkages are shown however: loop $\mathrm{A}$ indicates the formal collection of data describing the performance of the agricultural sector, thus providing feed-back from process III to process II. This component usually has some parallel in reality in the form of agricultural surveys, extension staff estimates, etc. The similar feed-back loop B from process II to process I, which would inform current researchers of the impact of previous research on planning decisions, is rarely present, even informally. A satisfactory link would require a conscious decision to allocate part of the research capacity to the evaluation of previous research. The difficulties of conducting completely rigorous analysis in this area are underlined by the model.

To examine the relationships between alternative research methodology $(\mathrm{X})$ and the social utility 


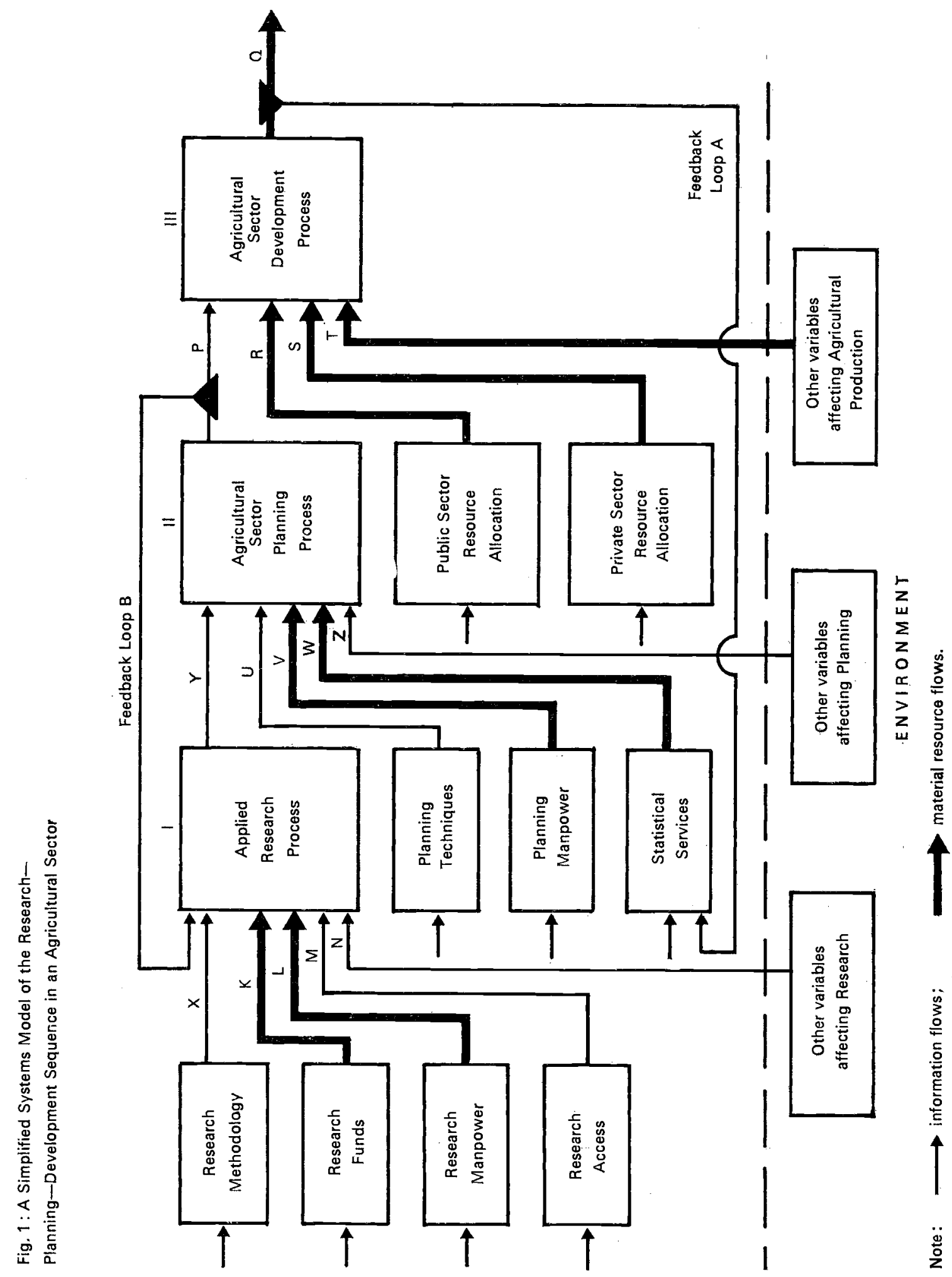


(Q) of the associated research, the analysis must be performed through three equations:

$$
\begin{aligned}
& \mathrm{Q}=\mathrm{f}(\mathrm{P}, \mathrm{I}, \mathrm{R}, \mathrm{S}, \mathrm{T}, \mathrm{)} \\
& \mathrm{P}=\mathrm{f}(\mathrm{Y}, \mathrm{I}, \mathrm{U}, \mathrm{V}, \mathrm{W}, \mathrm{Z}) \\
& \mathrm{Y}=\mathrm{f}(\mathrm{X}, \mathrm{I}, \mathrm{K}, \mathrm{L}, \mathrm{M}, \mathbf{N})
\end{aligned}
$$

The difficulties facing a rigorous analysis of this relationship are obvious. A preliminary attempt at the task may be feasible if the empirical material is restricted to a relatively small research field in one part of the Third World. As a casestudy, therefore, 10 years or so of applied research for agricultural development in the three East African countries is briefly reviewed.

Taking the quantifiable aspects of research funds $(\mathrm{K})$ and manpower (L) first, there was a remarkable growth of applied economic and other social science research in the agricultural sectors of the three Eastern Afriçan countries between 1965 and 1970. In the main this was associated with applied research institutes at the universities, although some regional or programme teams with a research component were based inside government. ${ }^{1}$ Bohnet and Reichelt's (1972) review of applied research conducted in East Africa between 1965 and 1969 reveals that applied economics research was carried out at the three university research institutes as follows ${ }^{2}$ :

Institute for Development Studies, Kenya :

101 economics research projects, 29 in the agricultural sector.

Economic Research Bureau, Tanzania :

102 economics research projects, 32 in the agricultural sector.

Makerere Institute of Social Research, Uganda : (including MISR projects in Kenya and Tanzania) 189 economics research projects, 48 in the agricultural sector.

Whilst the scale of economics research has declined in Uganda since 1971/72 (for recent problems in field work, see Schultheis, 1974) activity in both Kenya and Tanzania has accelerated since 1969. In 1974, for example, the University of Nairobi had 25-30 active agricultural economics research projects, and the University of Dar es Salaam 15-20 live projects in the same field. Economic research activity on this increased scale was made possible by:

(i) an influx of finance from a wide variety of multilateral and bilateral sources at zero opportunity cost to the East African countries;

(ii) the cooperation and encouragement of government planners and administrators;

(iii) the ability to attract some experienced expatriate researchers, and a growing demand for research qualifications by East Africans themselves.
Researchers' access (M) to agricultural development problems has been good in all three countries for most of the post-independence period, with senior staff sitting on a variety of government planning committees and special commissions, and research being commissioned by governments. Agricultural planning expertise (V) has also grown very rapidly since the early 1960s. At independence only Uganda had an agricultural economist involved in central planning and policymaking. Agricultural planning now takes place at two and, for major projects, at three levels. Each Ministry of Agriculture has an economic planning unit or division with 8-15 established posts; there is a further group of agricultural economists in the planning ministry, and most major projects submitted for donor funding and/or technical assistance will be subject to on-site examination by feasibility and appraisal missions which usually attempt to apply standard cost-benefit appraisal procedures (Gittinger 1972). Resources for the collection of basic agricultural statistics (W) have also improved considerably. Combined teams of local and expatriate statisticians with specialized responsibility for this area are established in the central statistical bureaux; in Kenya and Tanzania funds and enumerators have been sufficient to generate a considerably increased flow of data, although in practice major delays have occurred in analysing and presenting survey data. In Ugailda resources have been more limited since the 1963-65 agricultural census work, which received United Nations technical assistance, was completed in 1966.

\section{Deficiencies in Agricultural Planning in East Africa}

The resources available for applied research, planning and basic data collection in the agricultural sectors in East Africa are relatively good for less developed countries as a whole, and outstandingly good for Africa. Nevertheless, serious deficiencies remain in current agricultural planning. Since these cannot be attributed to scarcity of resources, East Africa can be viewed as a testing ground for the hypothesis that it is organizational and procedural factors which primarily affect the ultimate productivity of applied research in the agricultural development process. The major observed deficiencies in planning techniques

\footnotetext{
1 E.g. the Dutch and West German farm advisozy teams in western Kenya; the Nordic agricultural economics research at Mbeya and economic research under the National Water Resources Council in Tanzania. (In practice the borderline between applied research and pre-planning work in government is a difficult cne to draw; much work in government could be classified as applied research, depending on the definition be classin
used.)

2 The distribution of research projects within the agricultural economics field has bean reviewed elsewhere (Belshaw, 1973).
} 
(U) and planning data (feed-back loop A) are discussed first.

The deficiencies in agricultural sector planning techniques which have consistently recurred are as follows :

(i) The quantity of scarce high-level agricultural manpower required to implement the proposed agricultural projects is not related to future supply, i.e., there is a failure either to use manpower budgets to ensure sufficient agricultural expertise or to recognise manpower as a constraint on the number of projects which can be implemented.

(ii) Product and factor price setting is not fully integrated as an instrument of agricultural planning; typically, agricultural prices are residuals from fiscal policy or commodity stabilization objectives.

(iii) Project identification often starts with an existing institution or technique, e.g., cooperative societies, tractors, etc. rather than being output oriented, based upon the identification of new markets or changes in demand.

(iv) Development programmes with disproportionally large recurrent expenditure such as agricultural extension or agricultural research are rarely subjected to formal benefit-cost appraisal procedures; these are usually required for the larger capital-intensive projects, tending to bias the identification and selection of projects towards the latter.

(v) Perspective planning is typically absent; this prevents matching the adequacy of mediumterm plan targets (e.g. for employment and income distribution) against the long-run implications of population growth for the use of increasingly scarce land and water resources.

(vi) The agricultural sector plan itself is usually prepared as a policy rather than as an action document, i.e., it does not prescribe the sequence of actions required to implement the plan. Nor is the plan revised in the light of formal evaluation of implementation (Chambers 1972).

Concerning the supply of basic data available to agricultural planners, four endemic problems can be observed:

(i) The continuing absence of reliable acreage, yield and production data for most crops produced on small farms prevents reliable output forecasting and cost-benefit analysis of small-farm improvement programmes. $E x$ post evaluation of plan and project performance is also extremely hazardous given the absence of reliable 'baseline' data. These problems are particularly severe where there appears to be a comfortably large array of data, as in Uganda, but where flaws in the statistical methods reduce its reliability (Belshaw 1975).

(ii) Generally, information is lacking from which to infer possible rates of diffusion of technological innovations and 'learning curve' effects in the farming community. Consequently, cost-benefit appraisal of many capital-intensive projects as well as all smallfarm improvement projects has to fall back on crude judgments of the probable effects of alternative techniques, since output is strongly dependent on farmers' rates of adoption acquisition of skills and choice of the level and intensity of production.

(iii) The increasing commitment to disaggregated regional planning for the rural areas of East Africa requires the definition of reasonably homogeneous farming-system zones. Regional planning requires that data from national statistical programmes-agricultural censuses, household budget surveys, etc.-can be related to these zones, as well as to the customary administrative sub-divisions of each country. To date, the coverage and quality of both basic environmental data and farm system data are inadequate for this purpose. ${ }^{3}$

(iv) Much useful data about the immediate environment, performance and impact of public sector programmes exists but is not collected systematically to provide continuous feedback and evaluation for the planning process. Data gaps of this kind can be plugged by relatively simple changes in project management and reporting procedures (Chambers 1974). Steps have been taken in Kenya recently to institute changes in field level management procedures as a result of applied research. In Tanzania improved management and annual planning systems have been introduced on a nationwide basis although these have not yet penetrated below the level of the District headquarters. A rural development project in Lushoto District, however, has introduced field procedures developed in Kenya.

\footnotetext{
3 Since 1970 attempts to define relatively homogeneous crop ecological or farming zones have been made for Uganda by E. M. Kulp (unpublished papers), for Tanzania by Diana Conyers and others (BRALUP Research Reports) and for Kenya by J. Exeter and R. Nelson (Kenya Government, unpublished papers). Whilst these efforts are advances on previous approaches, all the proposed schemes must be viewed as still at a preliminary stage. In this writer's view, this task cannot satisfactorily be completed until it is taken into account in the design of the sampling frames of the national agricultural 'censuses'.
} 


\section{Deficiencies in Applied Research for Agricultural Development}

We can now turn to the central component of the model, the output of applied research intended to be useful to agricultural planners (Y). Frequently, applied research does not yield the information required by the agricultural planners, or does not provide it at the time or in the form required. In some cases, research results are unrealistic or counter-productive because one of the multiple disciplinary inputs required is missing.

(i) Agricultural experimental cata do not indicate outputs obtainable under practical farming decisions and may even generate unprofitable practices because production economics analysis has not been integrated into research of this kind (Belshaw and Hall 1972).

(ii) Priorities for agricultural scientific research tend to be determined by reference to 'disciplinary' rather than development criteria (Bohnet and Reichelt 1972). This partly reflects the absence of work on operational appraisal procedures for scientific research projects.

(iii) Farm-level socio-economic research is too infrequently incorporated into a macro-frame which will permit 'positive' predictions of agricultural sector performance, as well as the more usual focus on 'normative' farm planning.

(iv) Much applied research, especially when conducted in a university context, takes a considerable time to publish. This time-lag often affects the relevance of results. Although this problem has been partially solved by the production of mimeographed working papers in the course of research, these cannot transmit the findings of large surveys.

(v) Both economic and technical research findings are handed over to an executive department of government for appraisal and implementation; considerable further work may be involved: "Whatever Development Institutes investigate or propose, if it is useful, it will eventually require translation into a budgetary or balance of payments process, as well as into other policies" (Stolper 1967: 135). Since executive capacity in government is itself a critically scarce resource (Chambers 1966), there is a serious risk that no action will be taken on research findings.

Obviously, an improvement in research productivity will not in itself guarantee a major improvement in agricultural planning performance, given the problems already cited with planning techniques and basic data. Yet often it is concluded that still more applied research is required.
For example, some agricultural economists argue that the existence of a more comprehensive array of data from applied economic and technical studies would permit the exploration through computer simulation models of the effects of alternative policies and changes in other exogenous variables on agricultural sector performance. In particular, the specification of the conditions (cspecially productivity, costs and prices), under which new production activities would become socially and/or privately profitable, would enable early identification of projects prior to more intensive work on project design, trials, etc. (see e.g. Manetsch et al. 1971). Further improvement in agricultural planning in most LDCs, the argument runs, rests heavily on further investment in data and applied research. It is, however, hard to resist the view that such a conclusion rests as much on technical criteria or personal interest as on economic analysis when the total data-collecting and research resources required outstrip the available funds, and the experienced high-level manpower which could be made available in a typical LDC is strictly limited (see, for example, the comment by Anderson (1974: 36) on the work of Manetsch et al). Before the 'more research' argument is accepted, therefore, it is necessary:

(i) to examine whether existing research resources cannot provide more relevant and timely results for the planner;

(ii) to identify, if possible, more efficient forms of investment in applied research activity;

(iii) to explore alternative low-cost sources of information.

These possible changes in the methodology of applied research (X) are examined first against some general propositions in the published contributions to this debate, and second with reference to recent experience with applied research on rural development planning in Kenya.

\section{The Causes of Ineffective Applied Research}

An alternative explanation for the malaise in development research is fairly widespread in the recent literature. The problem is viewed essentially in cultural terms; the research methodology of the social sciences has been developed to be effective in western industrial countries, to solve those problems which are perceived as important by the elite. Data are relatively cheap to collect; a quantitative methodology is both feasible and, because it uses sophisticated techniques, confers prestige on the user. When this methodology is transferred to an LDC, excessive resources are committee to standardized surveys econometric analysis, etc., to produce data which falsely give the appearance of great accuracy and precision 
but which relate only to the quantifiable subsystem of a complexly interacting socio-economic system. The indigenous social scientists, it is concluded, must free themselves from the domination of alien intellectual traditions if they are to assist in solving the problems facing their own people.

This has been extensively argued by Pausewang (1973), who provides evidence from rural development research in Ethiopia. The problems identified are important, but both diagnosis and prescription appear to be dubious. In the first place, the epistemology of all problem-solving research is itself 'alien'; since the generation of research procedures which will find effective solutions to local problems is desired, it would seem counterproductive to allow applied scientific methodology to be discarded at the same time as inappropriate research techniques.

Secondly, there is of course a diversity of competing approaches to research along several interacting continua-basic or applied, qualitative or quantitative, mono-disciplinary or inter-disciplinary, short-term versus long-term -in western society even within the framework of any one particular Weltanschaung. Pausewang himself represents one particular 'alien' school; but presumably he would prefer Ethiopians to judge his own recommendations by their relevance and potential effectiveness for Ethiopian problems rather than by their intellectual origins.

The same issues raised by Pausewang are debated in the context of problem-solving research in western society. One such debate in one corner of the applied social sciences will suffice for illustration. In a discussion of agricultural economics research in the United States, under the question "Is methodology becoming an end in itself?", Paarlberg attacks precisely the same events identified by Pausewang - techniques in search of problems rather than vice-versa, inadequate attention to reality and underlying theory, unnecessary elaboration and sophistication.

Clearly, a precondition for effective problemsolving research is that society will reward researchers who actually assist towards the solution of problems. If this is met, as by and large it has been in East Africa, one must search for other impediments to the production of usable results and their application in problem-solving.

In the agricultural economics debate already referred to, one discussant refers to the need for extensive familiarity with the features of the problem under examination:

'Thus if we want to ... develop an interest and skill in attacking the tough economic problems of our time, we must have the opportunity to live and work with these problems'

(Abel 1963: 1404)

Living and working with the problem suggests an involvement not only with finding a potential solution but applying, testing and where necessary, modifying it until some acceptable amelioration of the problem occurs. It is the converse of dilettantism and preoccupation with ideas, and with numbers, for their own sake. It means, in other words, research and development as one process rather than two separate activities.

In his otherwise perceptive case-study of applied research effectiveness in Zambia, Fuglesang retains the idea of a finite terminal point for applied research-the production of the final report. But if research results require further creative inputs to be transformed into implementable programmes, in what sense can we say that the results are 'usable'? A research methodology which recognizes the responsibility of the research itself to work up solutions which can be demonstrated, in the $R$ and $D$ phase, to be implementable, provides a solution to this problem. There are a small number of examples in rural development work in LDCs where research has been conducted along these lines: the Comilla Project in Bangladesh and the 'Borgo a Mozzano' type projects for example in Nigeria and Thailand, are two examples; the Special Rural Development Project in Kenya is another.

\section{Applied Research with Implemented Solutions: An Example}

The Special Rural Development Programme (SRDP) operates in six experimental rural divisions chosen as representative of different major ecological/farming system zones in Kenya. Each area has a comprehensive rural development plan which is specially funded by untied bilateral aid through the Ministry of Finance and Economic Planning. The programme began in January 1971 and runs until July 1976 . The level of additional resources has been restricted, however, as it is a primary principle that new projects should use established staff and other recurrent resources as far as possible, so that successful projects can be widely replicated.

Two ways in which the SRDP has contributed to the methodology of applied social science research can be distinguished. First, it has provided six testbeds or laboratories for the trial of a variety of new projects in rural areas without the need to alter national-level policies or organizations. Because of their small scale, field trials have not encountered official resistance despite evidence 
that if the researcher is an outsider to the policymaking and implementation process, the acceptability of his advice is reduced (Bohnet and Reichelt 1972). The small scale of SRDP operations has enabled the researcher who claims to have a relevant research finding to test out his proposals on a pilot scale in advance of a major policy decision being taken.

There are several advantages to this additional research dimension provided by the SRDP areas. As already suggested, the research recommendations can more easily be carried through to a tested package ready for more widespread implementation. Bohnet has discussed the problem of a single researcher achieving an accurate problem-solving synthesis on the basis of the partial analysis of a single discipline (Bohnet and Reichelt 1972: 38, 39). As an alternative to interdisciplinary research teams, with their attendant costs, Bohnet advocates what he terms 'research in action'-the active participation of the researcher not only in the diagnosis but in the programming and implementation of the solution, while Hesselbach has advocated research based on participant observation of stimulated change for the study of individual farmers (Hesselbach 1972: 168). The SRDP framework allows these two approaches to be extended into the public decision-making domain. Other potential advantages are the creation of interest within the public and private sectors as the pilot project unfolds; the informal training of personnel working on the project, and the creation of a training base in the pilot project itself, should a decision be taken to replicate it more widely. At first sight, these benefits may appear to be more than offset by the additional work-load imposed on the researcher, and the possible reduction in research productivity. The participant research method, however, permits problem-solving through iterative approximation and makes redundant attempts to specify the variables in the field problem completely - a task which may be impossible for the single-disciplinary researcher in any case. In the orthodox approach the major part of the applied researchers' work-load is concerned with data collection and analysis. In the alternative approach the time saved by eliminating measurement of all but a few key indicator variables will at least partially offset the additional time spent in modifying the initial solution. 4

So far, the emphasis has been on the research opportunities provided for experimentation in pro4 This raises important issues, which cannot be pursued here,
concerning the type of research train ing required for iterative
field experimentation, and the problem of the low academic
status of the more intuitive or 'trial and error' procedures in such a methodolcgy. jects intended for wider replication in small-scale agriculture. In the six SRDP areas some 120 projects were being implemented at any one time. Only a minority of these were explicitly designed as experiments; examples include small-holder credit, labour-intensive road construction, 'agriservice stations' (low level input infrastructure), small-scale irrigation and inter-disciplinary agricultural research. Valuable feedback has also resulted from the implementation of fairly standard projects and from the design and implementation of the integrated rural development plan itself (i.e. a multi-sectoral mix of projects for one geographical area). The six area plans, therefore, provide a better framework for learning about higher-order systems than the individual projects. 5

The second implication of the SRDP for the methodology and impact of applied research can be illustrated from experience with the introduction of a set of management procedures for rural development planning (Belshaw and Chambers 1972). These were designed to provide an information and decision-making system for the main stages of formulating and implementing an integrated rural development plan. One of the evaluation procedures, the Annual Implementation Review, provides information on the performance of public sector activities timed to feed-in to the design of the following financial year's project operations. Another procedure, the Annual Evaluation Review, assesses the impact of public sector activities in terms of cost-effectiveness and social welfare criteria. It is timed to feed-in to the annual budget which allocates financial and manpower resources between projects for the ensuing financial year. One result of both procedures is the creation of much-improved feedback generated relatively cheaply by executive personnel. Under previous reporting procedures much additional data had to be collected by independent research resources if they were to be available at all. The data coverage cannot completely measure the final benefits of public sector activities which accrue in the private sector. Nevertheless, the assembly of project performance data in a form and at the time required for many planning decisions represents a worthwhile improvement on the usual official reporting system. In East Africa the latter is based on the calendar year, is of an ex post descriptive nature

\footnotetext{
5 Unfortunately, this dimension was overlooked by the first team of University of Nairobi researchers appointed to evaluate the SRDP (Ascroft et al. 1972). This has led to a significant under-assessment of the potential value of the SRDP $f \circ r$ rural and regional development planning by the Kenya Government A second University planning by the extensive evaluation in $1974 / 75$; their report is expected to be made available in 1976 .
} 
and feeds in to no specific decision-making process in government. Through reforming the reporting structure, it was possible to generate a body of usable data at virtually no additional cost, with a consequent saving in scarce research time.

Conversely, the same process identifies the kinds of data which executive personnel cannot obtain easily in the field. Some additional feedback can often be obtained at little extra cost e.g. small follow-up surveys of training course participants; farm visit reports or registers, etc. Information gaps identified can be ranked by the planner in the light of the potential importance of the project, and the degree of uncertainty surrounding its impact in terms of net social benefits or other policy criteria. The planner's research priorities can then be transmitted to research institutions, statistical offices, etc.

With specific data needs identified in advance, large-scale across-the-board evaluation would be unnecessary, at a considerable saving in research resources. This can be illustrated from the SRDP. In the evaluation review of the first year of operation 15 academic researchers took 11 months to deliver a report which was available for neither the annual programming nor the annual budget exercises (Ascroft et al. 1972). A significant proportion of this report duplicated information already reported by the executive field staff, and the main recommendations had not been tested under the experimental conditions which SRDP was specifically created to provide.

In summary, the prevalent methodology in development research is seen as an important contributory factor to its low social profitability. And there is no reason why the East African situation should be unique in this respect. Because 'action research' or the 'R \& D' approach places the researcher in an operational situation, the probability is greater that the results will be socially relevant, accurate and put to practical use. This methodology replaces the linear research sequence-in terms of the model in Figure 1-of moving from process I to process II and then on to process III by an iterative sequence I-III (small) -II-III (large). ${ }^{6}$ If the potential advantages are to be secured, then the planners must create opportunities for more effective research and researchers (and the trainers of researchers) must use them. This may entail marked differences in research conditions-longer periods in the field,

6 This has similarities to the iterative sequence II-III (small) -II-III (large), which is followed when a pilot project is introduced. However, the pilot project is not usually part of a problem-solving research operation where the final solution a problem-solving research operation where the final solution
is not known; rather it is a small-scale version of a final project. more team research, less emphasis on individual publications, different research skills, etc. Also, the rewards system for researchers will need considerable changes from the prevalent academic career model if more appropriate methodologies are to be adopted.

\section{References}

Abel, M. E., 1963, 'Is Methodology Becoming an End in Itself?' Journal of Farm Economies, 45, 5.

Anderson J. R., 1974, Simulation: Methodology and Application in Agricultural Economics, Review of Marketing and Agricultural Economics, 42, 1.

Ascroft, J. R., et al., 1973, An Overall Evaluation of the Special Rural Development Programme, Occasional Paper No. 8, Institute for Development Studies, Nairobi.

Belshaw, D. G. R., 1973, The State of Agricultural Economics Research in East Africa, in Mbilinyi, S. M. (ed), Agricultural Research for Rural Development, East African Literature Bureau, Nairobi.

-1975, Crop Production Data in Uganda: A Statistical Evaluation of International Census Methodology, Development Studies Discussion Paper No. 7, University of East Anglia.

Belshaw, Deryke and Robert Chambers, 1973, A Management Systems Approach to Rural Development Planning. Discussion Paper No. 161. Institute for Development Studies, Nairobi.

Belshaw, D. G. R. and Malcolm Hall, 1972, The Analysis and Use of Agricultural Experimental Data in Tropical Africa, East African Journal of Rural Development, 5, 1.

Bohnet, M. and H. Reichelt, 1972, Applied Research and its Impact on Economic Development: The East African Case, IFO Institüt für Wirtschaftsforschung, Munich.

Chambers, Robert, 1969, Executive Capacity as a Scarce Resource, International Development Review, 11, 2.

-1972, Planning for Rural Areas in Africa: Experience and Prescriptions, African Review, 1, 3.

-1974, Managing Rural Development: Ideas and Experience from East Africa, Scandinavian Institute of African Studies, Uppsala.

Fuglesang, Andreas, 1973, Nutrition-implementation Programmes as Communication Systems, in Vahlquist, Bo (ed), Nutrition: A Priority in African Development, Dag Hanmarskjold Foundation, Uppsala. 
Gittinger, J. Price, 1972, The Economic Analysis of Agricultural Development Projects, Johns Hopkins, Baltimore.

Hesselbach, J., 1972, Participant Observation as a Technique in Observing Decision-making, Sociologia Ruralis, 12.

Manetsch, T. J., et al., 1971, A Generalized Simulation Approach to Agricultural Sector Analysis with Special Reference to Nigeria, Michigan State University, East Lansing.

Paarlberg, Don, 1963, Is Methodology Becoming an End in Itself? Methodology for What? Journal of Farm Economics, 45, 5.
Pausewang, S., 1973, Methods and Concepts of Social Research in a Rural Developing Society, IFO Institüt für Wirtschaftsforschung, Munich.

Schultheis, M. J., 1974, Economics and Economic Research in Uganda during the Amin Period, African Studies Association (USA) Conference Paper (mimeo).

Stolper, W. F., 1966, Functional Interrelationships Between Development Institutes and Planning Organizations in Developing Countries, in Training and Research in Development, OECD, Paris. 